\title{
Assessment of central venous catheterization and complications in a tertiary pediatric intensive care unit
}

\author{
İlknur Tolunay ${ }^{1}$, R. Dinçer Yıldızdaş ${ }^{1}$, Hüseyin Elçi ${ }^{2}$ Derya Alabaz ${ }^{3}$ \\ ${ }^{1}$ Intensive Care Unit, Departments of ${ }^{2}$ Pediatrics and ${ }^{3}$ Pediatric Infectious Diseases, Çukurova University Faculty of Medicine, \\ Adana, Turkey.E-mail: ilknurtolunay@gmail.com \\ Received: 28th July 2017, Revised: 14th August 2017, Accepted: 30th August 2017
}

SUMMARY: Tolunay İ, Yıldızdaş RD, Elçi H, Alabaz D. Assessment of central venous catheterization and complications in a tertiary pediatric intensive care unit. Turk J Pediatr 2018; 60: 63-69.

In catheter-using units as pediatric intensive care, it is important to know the complications that may occur during the insertion and use of central venous catheterization (CVC), and to take appropriate measures in order to reduce the mortality and morbidity of critical patients. The aim of this study was to evaluate CVC and catheter related complications in our tertiary pediatric intensive care unit. For this prospective study, 155 central venous catheters and/or hemodialysis catheters used with 106 patients, between August 2014 and August 2015 were evaluated. Demographic information about patients, catheter insertion procedure and catheter related complications were recorded. Sixty-two $(58.5 \%)$ male and forty-four $(41.5 \%)$ female patients were evaluated in this study. The median age was 67.5 months (1-212). The mean dwell time of catheters was $10.54 \pm 8$ days. Twenty-two $(14.2 \%)$ catheters were removed from patients because of catheter related complications. The mean dwell time of complicated catheters was $10.6 \pm 8.5$ days and there was no statistically significant difference between complicated and non-complicated catheters. Catheter related blood stream infections was diagnosed in $5.1 \%$ $(8 / 155)$ patients and these catheters were removed from patients. Including these patients, positive blood culture was found to be at $14.2 \%(22 / 155)$. The mean dwell time of catheters with positive blood culture was $14.25 \pm 7.3$ days. The mean dwell time of catheters with positive blood culture was statistically significantly longer than catheters with negative blood culture. In the 3 patients who developed catheter thrombosis, 2 patients were followed up because of infection/sepsis and 1 patient had a neurological disease. Catheter thrombosis developed in 1 femoral vein and 2 internal jugular veins. The development of central venous catheter complications depends on many different factors and it is possible to reduce the complications with precautions taken during replacement and daily use.

Key words: central venous catheter, complication, infection, thrombosis, pediatric intensive care.

Central venous catheter (CVC) is an invasive instrument used for long term drug and fluid treatment, administration of blood and blood products, infusing of vascular irritating drugs or antibiotics, extracorporeal treatments as plasmapheresis and hemodialysis in critical patients at pediatric intensive care units. ${ }^{1-4}$ In catheter-using units as pediatric intensive care, it is important to know the complications that may occur during the insertion and use of CVC, and to take appropriate measures in order to reduce the mortality and morbidity of critical patients. With the widespread use of CVCs in pediatric intensive care units, catheter related complications are increasing. Various factors influence the development of complications. Complications due to CVC are divided into two groups as early and late complications. Early complications include arterial puncture, cardiac arrhythmia, hemorrhage, adjacent nerve damage, catheter malposition, air embolism, catheter breakage and pneumothorax 
can occur during catheter insertion while late complications are catheter infection, dysfunction and thrombosis. ${ }^{5}$ Handwashing and barrier precautions reduce the rate of catheter related blood stream infection (CRBSI) ${ }^{6,7}$ As the experience of the physician who inserts the catheter increases, the complication rate decreases. ${ }^{8,9}$ As the number of punctures increases, the complication rate increases. ${ }^{10}$ Using ultrasound during catheter insertion reduces the risk of mechanical complications and the number of punctures. ${ }^{11,12}$

In this study, we planned to evaluate the complications and associated factors related to CVC applied to patients in our intensive care unit.

\section{Material and Methods}

Between August 2014 and August 2015, 155 catheters applied to 106 critical patients who were admitted to our tertiary care intensive care unit were prospectively evaluated. Patient information as age, gender, diagnosis of admission to intensive care unit and mortality rate were recorded. In addition, anatomic side, person who placed the catheter (as pediatrician, pediatric intensive care fellow, associate professor or professor), barrier precautions, disinfection method, fluids applied from catheter, catheter dwell time and the reason for the removal of the catheter were recorded. The complication type, duration of complication, and whether the catheter was removed was also recorded.

All catheters were inserted in our pediatric intensive care unit by a pediatrician, pediatric intensive care fellow, associate professor or professor. The procedure was carried out using the Seldinger technique and selected regions according to the patient and practitioner. Central venous catheter indications were;
1- multiple and continuous administration of drugs, such as antibiotics, inotropes and fluids 2- hemodiafiltration. Complications related to the central venous catheter were divided into 4 groups as catheter dysfunction, bleeding and thrombotic complications, infection and others.

Non-infectious complications such as swelling, obstruction and malrotation were accepted as catheter dysfunction. Failure of fluid infusion from catheter or failure to allow rate of blood entry/exit flow for hemodialysis has been considered as obstruction.

Bleeding, vascular injury, thrombosis or hemothorax were accepted as bleeding and thrombotic complications. Thrombosis has been accepted as ultrasonographic observation of the thrombus in deeply located venules or absence of intraluminal blood flow by ultrasonography.

In a patient with intravenous catheter, the presence of bacteremia/ fungemia diagnosed with at least one peripheral blood culture positivity and accompanying clinical infection findings (fever, chills, and/or hypotension) and absence of any other source of infection other than catheter has been accepted as CRBSI (Table I). ${ }^{13,14}$

Nerve injury, arrhythmia, pneumothorax and cardiac tamponade were other problems

\section{Statistical Analysis}

Statistical analysis was performed using SPSS16.0. Categorical variables were provided as numbers and percentages, numerical variables were given as mean \pm standard deviation or median (minimum-maximum), followed by comparative analysis with chi-square test. Continuous data were analyzed with the MannWhitney U or Kruskall-Wallis when the data were not normally distributed and analyzed with One-way ANOVA when the data were not normally distributed. $\mathrm{p}<0.05$ was considered

Table I. Diagnostic Criteria of Catheter-Related Bloodstream Infection.

- The same organism recovered from percutaneous blood culture and from quantitative ( $>15$ colonyforming units) culture of the catheter tip;

- The same organism recovered from a percutaneous and a catheter lumen blood culture, with growth detected 2 hours sooner (i.e., 2 hours less incubation) in the latter;

- The same organism recovered from a quantitative percutaneous and a catheter lumen blood culture, with 3-fold greater colony count in the latter 
statistically significant.

Written informed consent was not obtained due to the retrospective nature of this study. The ethics committee approval for the study was obtained from Local Ethics Committee of NonInterventional Clinical Studies on September 5th, 2014, number 34.

\section{Results}

Between August 2014 and August 2015, 155 catheters, applied to 106 critical patients, were prospectively evaluated. More than one catheter was required for $34.9 \%(37 / 106)$ of the patients. In this study, $62(58.5 \%)$ male and $44(41.5 \%)$ female patients were evaluated. The median age was 67.5 (1-212 months) months. The diseases of patients were $33.6 \%$ (39/116) infection/sepsis, $24.1 \%(28 / 116)$ neurological diseases, $11.2 \%(13 / 116)$ drug poisoning/trauma/scorpion envenomation, $8.6 \%(10 / 116)$ renal diseases, $7.8 \%(9 / 116)$ endocrine/metabolic diseases, $6.0 \%$ (7/116) oncologic diseases, $3.5 \%$ (4/116) respiratory diseases, $1.7 \%(2 / 116)$ cardiologic diseases, $1.7 \%(2 / 116)$ hematologic diseases, $0.9 \%$ (1/116) immune deficiency, $0.9 \%$ (1/116) hepatic failure. Ten patients with two different diagnoses were included in the two diagnostic groups (Table II).

The insertion of a catheter is required for multiple and continuous administration of drugs such as: antibiotics, inotropes, and fluids at a rate of $94.2 \%(146 / 155)$. Of the 155 procedures included in the study, $72.9 \%(113 / 155)$ had CVC insertion and $27.1 \%(42 / 155)$ had dialysis catheter insertion. Anatomic site was $57.4 \%$ (89/155) femoral vein, $30.3 \%$ (47/155) internal jugular vein and $12.3 \%(19 / 155)$ subclavian vein. Barrier precautions have been used in all processes involved in the study. For disinfection, chlorhexidine was used in $93.5 \%(145 / 155)$ of procedures while povidone iodine was $6.5 \%(10 / 155)$. The mean dwell time of 155 catheters was $10.54 \pm 8$ (1-48) days. There was no statistically significant difference between the mean dwell time of 155 catheters and age, gender, diagnosis of admission to intensive care unit, anatomic side and person who placed the catheter.

The reason for the removal of the catheter were $68.4 \%(106 / 155)$ end of the indication, $14.2 \%(22 / 155)$ complication development, $2.6 \%(4 / 155)$ spontaneous removal and $14.8 \%(23 / 155)$ exitus of patients. Twentythree complications were observed in 22 catheters that removed from the patient due to complications. These complications were $52.2 \%(12 / 23)$ catheter dysfunction, $30.4 \%$ $(7 / 23)$ infection, $8.7 \%(2 / 23)$ bleeding and thrombosis, $4.3 \%(1 / 23)$ pneumothorax and one catheter $(4.3 \%)$ had both infection and thrombosis. In 12 patients who had catheter removal due to catheter dysfunction, $91.7 \%$

Table II. Reason of Admission to Pediatric Intensive Care Unit.

\begin{tabular}{lll}
\hline Disease & $\mathrm{N}$ & $\%$ \\
\hline Infection/sepsis & 39 & 33.6 \\
Neurological diseases & 28 & 24.1 \\
Drug poisoning/trauma/scorpion envenomation & 13 & 11.2 \\
Renal diseases & 10 & 8.6 \\
Endocrine/metabolic diseases & 9 & 7.8 \\
Oncologic diseases & 7 & 6.0 \\
Respiratory diseases & 4 & 3.5 \\
Cardiologic diseases & 2 & 1.7 \\
Hematologic diseases & 2 & 1.7 \\
Immune deficiency & 1 & 0.9 \\
Hepatic failure & 1 & 0.9 \\
Total & 116 & 100 \\
\hline
\end{tabular}


(11/12) obstruction and 8.3\% (1/12) swelling were observed.

The mean dwell time of complicated 22 catheters was $10.6 \pm 8.5$ days and there was no statistically significant difference between complicated and non-complicated catheters. There was no statistically significant difference between complication development and age, gender, diagnosis of admission to intensive care unit, anatomic side and person who placed the catheter.

Catheter related blood stream infection was diagnosed in $5.1 \%(8 / 155)$ of patients and these catheters were removed from patients. Including these patients, positive blood culture was found to be at $14.2 \%(22 / 155)$. The mean dwell time of catheters with positive blood culture was $14.25 \pm 7.3$ days and the mean dwell time of catheters with positive blood culture was statistically significantly longer than catheters with negative blood culture $(\mathrm{p}=0.004)$.

In three patients who developed catheter thrombosis, 2 patients were followed because of infection/sepsis and 1 patient had neurological disease. Catheter thrombosis developed in 1 femoral vein and 2 internal jugular veins. There was no statistically significant difference between catheter thrombosis development and age, gender, or diagnosis of admission to intensive care unit.

In our study, there was a patient $(4.3 \%)$ who developed pneumothorax due to subclavian catheter insertion. This patient did not need chest tube placement and was discharged after the treatment was completed. No patient developed nerve injury, arrhythmia or cardiac tamponade due to central venous catheter insertion.

\section{Discussion}

Central venous catheters are the most commonly used interventional treatment instruments in intensive care units. In pediatric intensive care units, the most common nontunneled CVCs are used, and catheter is placed to subclavian vein, internal jugular vein or femoral vein. ${ }^{15,16}$ According to the literature, CVC usage rates range from 32 to $80 \% .{ }^{17}$ Central venous catheters that provide convenience in the treatment and follow- up of critically ill patients may lead to an increase in the mortality and morbidity of patients due to their complications. Jain et al. ${ }^{18}$ reported that, catheter-related complications rate was $19 \%$ including $7 \%$ infectious and $12 \%$ non-infectious complications (obstruction, malrotation swelling). Kim et al. ${ }^{19}$ reported rates of $12.8 \%$ infections and $18.3 \%$ of noninfectious complications. Ramadan et al. ${ }^{20}$ reported a rate of non-infectious complication of $11.4 \%$. In our study, the complication rate was $14.8 \%$, with $5.1 \%$ infection and $9.7 \%$ non-infectious causes. Our complication rates were found to be lower than the literature.

The mean dwell time is the most important factor of catheter prognosis. In Çıtak et al.'s ${ }^{21}$ study, the mean dwell time of catheters was found as $13.03 \pm 6.2$ days. İşgüder et al. ${ }^{1}$ reported that the mean dwell time of catheters was 11.5 (1-83) days. Anıl et al. ${ }^{22}$ reported that the mean dwell time of catheters was $10.2 \pm 7.5$ (8-33) days. In our study, the mean dwell time of catheters was $10.54 \pm 8$ (1-48) days, which is consistent with the literature. The mean dwell time of complicated catheters was $10.6 \pm 8.5$ days and there was no statistically significant difference between complicated and non-complicated catheters.

While the risk of mechanical complications is low in femoral catheters, the risk of infection is the same as in non-femoral regions. ${ }^{22-25}$ In our study, femoral catheters had mechanical complications in $7.8 \%(7 / 89)$, whereas mechanical complications were observed in $10.6 \%(5 / 47)$ of 47 catheters applied to internal jugular veins. There was no statistically significant difference between anatomic side and complication development.

The most important factor in CRBSI is skin flora and it is very important to provide skin antisepsis. Patients treated with chlorhexidine gluconate had lower rates of catheter colonization and CRBSI compared to patients treated with povidone iodine and alcohol. ${ }^{26,27}$ When chlorhexidine-alcohol and povidone iodine-alcohol were compared, CRBSI was lower in chlorhexidine-alcohol group ${ }^{28}$. In our study, 93.5\% (145/155) used chlorhexidine and 6.5\% $(10 / 155)$ used povidone iodine for disinfection. No statistically significant difference was found between complication development and disinfection method. Our results differ from 
the literature in that the number of patients using povidone iodine is very low.

Catheter-related infections are the most important complications related to CVC and lead to increased mortality and morbidity, prolongation of hospital stay, and increased treatment costs. ${ }^{29}$ In the United States (USA), the rate of CRBSI was reported as 1.8/1000 catheter days in pediatric intensive care units. According to the data of the General Directorate of Health Services of the Ministry of Health of Turkey, the rate of CRBSI was reported as $4.7 / 1000$ catheter days in 2012 . In the study conducted by Isgüder et al. ${ }^{1}$ with 120 catheters in 2014, the rate of CRBSI was found to be $4.6 / 1000$ catheter days. According to the results of our study, the rate of CRBSI is $4.8 / 1,000$ catheter days and this result is similar to that given by our country, being higher than the USA. It was reported that CRBSI is associated with skin contamination in short-term catheter use ( $<10$ days) while with colonization in long-term catheter use ( $>10$ days). ${ }^{30}$ Hand washing and site cleaning before the process, taking tight barrier precautions during the process is effective in reducing CRBSI. It has been reported that the use of "maximum sterile barrier precautions" consisting of a bone, mask, sterile gown, sterile gloves and large covers when placing a central venous catheter reduces the rate of CRBSI according to standard precautions (such as sterile gloves and small covers). ${ }^{6,7}$ In our unit, there are catheter insertion boxes containing bones, masks, sterile surgical sets, sterile gowns, perforated and non-perforated covers to be used as barrier precautions and these boxes are routinely used by practitioners during catheter insertion. All the processes included in the study were hand washed before the process and barrier precautions were used. We believe that implementing strict barrier precautions in pediatric intensive care is effective in reducing infection rates.

Prolonged dwell time of catheter increases risk of infection ${ }^{1}$. In our study, CRBSI was diagnosed in $5.1 \%(8 / 155)$ patients. Including these patients, positive blood culture was found in $14.2 \%(22 / 155)$. The mean dwell time of catheters with positive blood culture was $14.25 \pm 7.3$ days. The mean dwell time of catheters with positive blood culture was statistically significantly longer than catheters with negative blood culture $(\mathrm{p}=0.004)$. Avoiding unnecessary catheters and evaluating the patient's need for catheters on a daily basis and removing the catheter from the patient when the indication is no longer necessary is the best way to reduce the CRBSI. Patients who are in need of catheters, during medication and catheter care require special attention be paid to sterilization conditions. Staff working in pediatric intensive care should be included in regular education programs and surveillance programs should be implemented in cooperation with the infection control committee. ${ }^{31}$

In pediatric patients, CVCs are a major risk factor for the development of deep venous thrombosis. ${ }^{32}$ While $85 \%$ of deep vein thromboses are caused by central venous catheter, the ratio of deep vein thrombosis related to central venous catheter is not clear. In a review by Vidal et al. ${ }^{33}$ the rate of catheter thrombosis is $20 \%$. In our study, thrombosis was detected in 3 patients and this rate was found low according to the literature. According to the literature, in some studies thrombosis is detected by routine ultrasound scans, and in some studies, thrombosis is detected after clinical signs. We think that asymptomatic thrombosis escapes detection because the thrombosis detected by Doppler ultrasound participates in the study after the clinical finding in our study, so our rate is lower than the literature.

In conclusion, $\mathrm{CVC}$ usage should be considered as necessary in the follow-up and treatment of critically ill patients but it may also cause an increase in mortality and morbidity due to complications. Hand hygiene before the procedure, application of barrier measures during the procedure and proper skin antisepsis, careful sterilization during catheter use, proper catheter care, maintenance of continuity in the training of intensive care workers and daily evaluation of catheter necessity are effective methods of reducing catheter related complications.

\section{REFERENCES}

1. İşgüder R, Gülfidan G, Ağın H, Devrim İ, Karaarslan U, Ünal N. Çocuk yoğun bakım ünitesinde santral venöz kateterizasyon uygulamaları: Dört yıllık deneyim. 
Çocuk Acil ve Yoğun Bakım Dergisi 2014; 1: 31-38.

2. Hockberger RS. The model of the clinical practice of emergency medicine. Acad Emerg Med 2001; 8: 660681.

3. Acar F, Cander B, Girişkin S, Gül M. Acil serviste santral venöz kateter uygulamaları; geriye dönük bir çalışma. Acil Tıp Dergisi 2009; 8: 35-38.

4. Bishop L, Dougherty L, Bodenham A, et al. Guidelines on the insertion and management of central venous access devices in adults. Int J Lab Hematol 2007; 29: 261-278.

5. Randolph AG, Cook DJ, Gonzales CA, Pribble CG. Ultrasound guidance for placement of central venous catheters: A meta-analysis of literature. Crit Care Med 1996; 24: 2053-2058.

6. Boyce JM, Pittet D. Guideline for hand hygiene in health-care settings: Recommendations of the Healthcare Infection Control Practices Advisory Committee and the HICPAC/SHEA/APIC/IDSA Hand Hygiene Task Force. Infect Control Hosp Epidemiol 2002; 23: 3-40.

7. Raad II, Hohn DC, Gilbreath BJ, et al. Prevention of central venous catheter-related infections by using maximal sterile barrier precautions during insertion. Infect Control Hosp Epidemiol 1994; 15 (4 Pt 1): 231-238.

8. Sznajder JI, Zveibil FR, Bitterman H, et al. Central vein catheterization. Failure and complication rates by three percutaneous approaches. Arch Intern Med 1986; 146: 259-261.

9. Bo-Linn GW, Anderson DJ, Anderson KC, McGoon MD. Percutaneous central venous catheterization performed by medical house officers: a prospective study. Cathet Cardiovasc Diagn 1982; 8: 23-29.

10. Mansfield PF, Hohn DC, Fornage BD, Gregurich MA, Ota DM. Complications and failures of subclavian-vein catheterization. N Engl J Med 1994; 331: 1735-1738.

11. Hind D, Calvert N, McWilliams R, Davidson A, Paisley $\mathrm{S}$, Beverly C. Ultrasonic locating devices for central venous cannulation: meta-analysis. BMJ 2003; 327: 361-367.

12. Tolunay O, Okuyan MK, Çelik T, Mert MK, Gülek B, Çelik Ü. Use of ultrasound for central venous catheterization in pediatric intensive care unit; a single center experience. J Pediatr Emerg Intens Care Med 2015; 3: 127-132.

13. Cetinkaya Șardan Y, Güner R, Çakar N ve ark. Damar İçi Kateter İnfeksiyonlarının Önlenmesi Kılavuzu. Hastane İnfeksiyonları Dergisi 2013; 17: 233-279.

14. Gahlor R, Nigam C, Kumar V, Yadav G, Anupurba S. Catheter related bloodstream infections. Int J Crit Illn Inj Sci 2014; 4: 162-167.

15. Polderman KH, Girbes A. Central venous catheter use. Intensive Care Med 2002; 28: 1-17.

16. Timsit JF, Sebille V, Farkas JC, et al. Effect of subcutaneous tunneling on internal jugular catheterrelated sepsis in critically ill patients: A prospective randomized multicenter study. JAMA 1996; 276: 1416-
1420.

17. M. Climo, Diekema D, Warren DK, et al. Prevalence of the use of central venous access devices within and outside of the intensive care unit: results of a survey among hospitals in the prevention epicenter program of the Centers for Disease Control and Prevention. Infect Control Hosp Epidemiol 2003; 24: 942-945.

18. Jain SA, Shukla SN, Talati SS, Parikh SK, Bhatt SJ, Maka $\mathrm{V}$. A retrospective study of central venous catheters GCRI experience. Indian J Med Paediatr Oncol 2013; 34: $238-241$

19. Kim HJ, Yun J, Kim HJ, et al. Safety and effectiveness of central venous catheterization in patients with cancer: Prospective observational study. J Korean Med Sci 2010; 25:1748-1753.

20. Ramadan H. Acil Serviste Santral Venöz Kateter Uygulanımı ve Komplikasyon oranları. Uzmanlık Tezi, Hacettepe Üniversitesi Tıp Fakültesi Acil Tıp Anabilim Dalı, 2010.

21. Citak A, Karaböcüoğlu M, Uçsel R, Uzel N. Central venous catheters in pediatric patients-subclavian venous approach as the first choice. Pediatr Int 2002; 44: 8386

22. Anil AB, Anil M, Kanar B, et al. The evaluation of central venous catheterization complications in a pediatric intensive care unit. Turk Arch Ped 2011; 46: 207-211.

23. Traore O, Liotier J, Souweine B. Prospective study of arterial and central venous catheter colonization and of arterial- and central venous catheter-related bacteremia in intensive care units. Crit Care Med 2005; 33: 1276-1280.

24. Breschan C, Platzer M, Jost R, Schaumberger F, Stettner H, Likar R. Comparison of catheter-related infection and tip colonization between internal jugular and subclavian central venous catheters in surgical neonates. Anesthesiology 2007; 107: 946-953.

25. Venkataraman ST, Thompson AE, Orr RA. Femoral vascular catheterization in critically ill infants and children. Clin Pediatr 1997; 36: 311-319.

26. Maki DG, Ringer M, Alvarado CJ. Prospective randomised trial of povidoneiodine, alcohol, and chlorhexidine for prevention of infection associated with central venous and arterial catheters. Lancet 1991; 338: 339-343.

27. Mimoz O, Pieroni L, Lawrence C, et al. Prospective, randomized trial of two antiseptic solutions for prevention of central venous or arterial catheter colonization and infection in intensive care unit patients. Crit Care Med 1996; 24: 1818-1823.

28. Mimoz O, Lucet JC, Kerforne T, et al. Skin antisepsis with chlorhexidine-alcohol versus povidone iodinealcohol with and without skin scrubbing for prevention of intravascular-catheter-related infection (CLEAN): An open-label, multicenter, radomised, controlled, two by two factorial trail. Lancet 2015; 386: 2069-2077.

29. Coccaro M, Bochicchio AM, Capobianco AM, Di Leo P, Mancino G, Cammarota A. Long-term infusional systems: Complications in cancer patients. Tumori 2001; 87: 308-311. 
30. Bouza E, Burillo A, Muñoz P. Catheter-related infections: diagnosis and intravascular treatment. Clin Microbiol Infect 2002; 8: 265-274.

31. Eggimann P, Pittet D. Overview of catheter-related infections with special emphasis on prevention based on educational programs. Clin Microbiol Infect 2002; 8: 295-309.
32. Hanson SJ, Punzalan RC, Arca MJ, et al. Effectiveness of clinical guidelines for deep vein thrombosis prophylaxis in reducing the incidence of venous thromboembolism in critically ill children after trauma. J Trauma Acute Care Surg 2012; 72: 1292-1297.

33. Vidal E, Sharathkumar A, Glover J, Faustino EVS Central venous catheter-related thrombosis and thromboprophylaxis in children: A systematic review and meta-analysis. J Thromb Haemost 2014; 12: 10961109. 